\title{
The Radicalization of Irish Drama 1600-1900
}

\section{Alexandra Poulain}

\section{(2) OpenEdition}

\section{Journals}

\section{Édition électronique}

URL : http://journals.openedition.org/etudesirlandaises/1897

DOI : 10.4000/etudesirlandaises. 1897

ISSN : 2259-8863

\section{Éditeur}

Presses universitaires de Caen

\section{Édition imprimée}

Date de publication : 30 juin 2010

Pagination : 178-180

ISSN : 0183-973X

\section{Référence électronique}

Alexandra Poulain, «The Radicalization of Irish Drama 1600-1900 », Études irlandaises [En ligne], 35-1 | 2010, mis en ligne le 30 septembre 2010, consulté le 21 septembre 2020. URL : http://

journals.openedition.org/etudesirlandaises/1897; DOI : https://doi.org/10.4000/etudesirlandaises. 1897

Ce document a été généré automatiquement le 21 septembre 2020.

\section{(c) (i) (2)(2)}

Études irlandaises est mise à disposition selon les termes de la Licence Creative Commons Attribution - Pas d'Utilisation Commerciale - Partage dans les Mêmes Conditions 4.0 International. 


\title{
The Radicalization of Irish Drama 1600-1900
}

\author{
Alexandra Poulain
}

\section{RÉFÉRENCE}

Desmond Slowey, The Radicalization of Irish Drama 1600-1900, The Rise and Fall of Ascendancy Theatre, Dublin, Irish Academic Press, 2008, 268 p., ISBN 978-0-7165-2957-6

1 L'ouvrage de Desmond Slowey s'inscrit dans le mouvement actuel d'un renouveau de l'historiographie théâtrale irlandaise qui s'efforce de remettre à jour un canon oublié antérieur à la création de l'Abbey, contestant l'idée longtemps dominante qu'il n'y aurait pas eu de théâtre irlandais spécifique (distinct du canon britannique) jusqu'à l'orée du vingtième siècle. Examinant dans son contexte historique et idéologique un vaste corpus de textes relativement méconnus, il montre que le théâtre fut pendant trois siècles le lieu où l'Ascendancy anglo-irlandaise se parla à elle-même, et mit à l'épreuve son identité dans un rapport dialectique avec l'Angleterre puis, progressivement, avec la classe moyenne et finalement le prolétariat irlandais.

2 Les deux premiers chapitres, portant sur les pièces du début du dix-septième siècle et de la Restauration, font revivre un théâtre tout entier tourné vers le devenir de la classe aristocratique et ses rapports avec le pays d'origine et la terre d'adoption. Slowey montre que la Tragédie héroïque, qui tend à exalter l'aristocratie, demeura une forme privilégiée au service de l'idéologie de l'Ascendancy en Irlande longtemps après que la mode en fut passée en Angleterre; à l'inverse, le terrain était fort peu propice à la comédie, naturellement subversive, qui triomphait sur la scène anglaise: aussi Farquhar, Southerne et Congreve se rendirent-ils à Londres pour y faire jouer leurs comédies qui ne rencontraient pas de public en Irlande.

3 Les chapitres trois à cinq s'intéressent aux premiers dramaturges à avoir exalté une identité irlandaise à la fin du dix-septième siècle et au début du dix-huitième : William Philips dans St Stephen's Green et George Farquhar dans Love and a Bottle, affirmant tous 
deux après Molyneux la valeur morale égale des aristocraties anglaise et irlandaise ; puis Charles Shadwell, dont les comédies irlandaises, épousant l'idéologie libérale du parti Whig, mettent en scène la nouvelle haute bourgeoisie qui succède à l'aristocratie à la tête du pays après la Glorieuse Révolution, et qui constitue le nouveau public des théâtres irlandais. Shadwell est aussi le premier dramaturge à militer pour une redéfinition plus inclusive de l'identité irlandaise, à la faveur d'une fusion entre l'aristocratie gaélique et la nouvelle bourgeoisie anglo-irlandaise. Le mythe fondateur de l'Ascendancy, selon lequel l'Angleterre serait venue apporter la civilisation aux barbares irlandais, est alors remplacé par le nouveau mythe de Hibernia, qui réinvente la nation irlandaise sur la base d'une collaboration librement consentie entre les groupes ethniques qui cohabitent sur l'île.

4 Le sixième chapitre porte sur la fructueuse seconde partie du dix-huitième siècle, au cours de laquelle Thomas Sheridan, son fils Richard Brinsley Sheridan, Richard Cumberland et Charles Macklin s'interrogèrent sur la nature du Gentilhomme irlandais, faisant de la "générosité " son trait distinctif. Slowey montre aussi comment les stratégies linguistiques des dramaturges, prêtant à leurs personnages une langue plus ou moins distincte de l'anglais d'Angleterre, participe de la construction ou de la contestation de stéréotypes identitaires; l'analyse du «brogue», en particulier, est passionnante.

5 Les derniers chapitres (sept à neuf) sont consacrés au dix-neuvième siècle au cours duquel le découpage de la société irlandaise en classes sociales prend progressivement le dessus sur les questions ethniques. D'inspiration explicitement révolutionnaire, les pièces de John O'Keefe furent les premières à recentrer le débat identitaire à la scène sur les divisions de classes, anticipant en cela les « liberty plays » de Sheridan Knowles, qui ne visent pas spécifiquement la situation en Irlande, mais dénoncent l'exploitation des classes les plus démunies par une aristocratie peu scrupuleuse dans l'ensemble du Royaume-Uni. Le dix-neuvième siècle voit l'épanouissement du genre mélodramatique, qui fleurit avec Boucicault qui montre une Ascendancy en ruines. A partir d'une analyse de ses héros anglo-irlandais ambigus, à la fois séduisants mais peu entreprenants et fondamentalement "décoratifs", Slowley montre que l'enjeu réel des mélodrames de Boucicault est la tension entre bourgeoisie et prolétariat ; l'Ascendancy y reste le pôle de référence, mais elle n'a plus aucune initiative dans ce jeu et ne demeure que comme une survivance d'un passé révolu. Cette disparition annoncée de l'Ascendancy s'achève dans les mélodrames nationalistes des successeurs de Boucicault au Queen's Theatre, souvent inspirés par la figure emblématique de Wolfe Tone ou par ses épigones. Ce dernier chapitre modifie sensiblement le mythe selon lequel la création de l'Abbey serait venue combler un vide dans le paysage culturel irlandais. Slowley y rappelle que les mélodrames nationalistes connaissaient un succès phénoménal et touchaient un très large public; le Queen's Theatre fut considéré par son public comme le théâtre national irlandais longtemps après la création de l'Abbey, souvent considéré comme un instrument idéologique au service de l'Ascendancy par un public dublinois majoritairement peu réceptif à sa vision élitiste. Paradoxalement, Slowey montre qu'une pièce telle que Cathleen ni Houlihan n'avait rien pour surprendre un tel public, rompu à la rhétorique sacrificielle en vogue dans les mélodrames du Queen's. C'est ce même public formé au Queen's, qui devait rejeter vigoureusement les pièces des " grands iconoclastes » du début du vingtième siècle, Synge, O'Casey, Shaw et Johnston, dont la réception se trouve ainsi salutairement remise en perspective. 
6 D'inspiration historiographique plus que dramaturgique, cet ouvrage très richement documenté invite donc à la fois à la découverte de tout un corpus longtemps négligé, et à la relecture de «classiques » (bien que Goldsmith ou Congreve ne soient mentionnés qu'en passant) resitués dans leurs rapports avec leurs contemporains. 